\title{
A test system for the biological safety cabinet
}

\author{
S. W. B. NEWSOM
}

From the Sims Woodhead Memorial Laboratory, Papworth Hospital, Papworth Everard, Cambs

SYNOPSIS A simple, cheap and readily available test system for biological safety cabinets is described. It depends on the containment of an aerosol of Bacillus subtilis spores generated in a BIRD micronebulizer and the measurement of air flows with an anemometer. The system was set up to survey new equipment but equally valuable results have been obtained from tests during use. New units were often badly installed and used equipment was poorly maintained. It is suggested that any department which has a need for a biological safety cabinet must be in a position to test its function.

Several types of biological safety cabinet are currently available and other, older models are in routine use in laboratories throughout the country. Most of them work by exhaustion of air away from the user (Williams and Lidwell, 1957), and the impaction of entrained matter on a high efficiency particulate air (HEPA or absolute) filter, capable of retaining particles of $0 \cdot 3-3 \mu$ diameter with a $99.997 \%$ efficiency or better at rated throughput. The treated air can be returned to the room or ducted outside. Some use a laminar flow of filtered air, which may be re-cycled through the machine, to protect the user and the test materials. Finally a few models have relied on the incineration of exhaust air instead of filtration.

The ability to test the safety of a cabinet is vital, either for a new installation or in-use tests on existing equipment. Safety, in practical terms, is the ability to contain an aerosol of pathogenic microorganisms; it depends on the airflow through the unit and the integrity of the constituent seals and filters. The pattern of airflows and the presence of gross leaks can be demonstrated easily with titanium tetrachloride smoke. An anemometer is needed to measure air velocity. The simplest type is a set of rotating vanes which wind a pointer round a dial while a more complex electronic version uses vanes to generate electrical impulses and provide a direct reading and recordable output. Thermo-anemometers depend on the cooling of a hot wire or a thermistor bead by the air; these also provide a direct readout and sample a much smaller area. Filter integrity is measured by the British Standard sodium-flame test (BS 3928). A special test bed is required but filters may become damaged in transit or use and so while the standard is valuable for new filters it has little relevance to the laboratory situation. However, Received for publication 25 April 1974. a portable photometer is now available (Moore Ltd, Wallisdown Road, Bournemouth), to adapt the test for laboratory use (Dyment, personal communication) at a cost of $£ 1000$. Two of the other possible in-situ tests require expensive equipment, namely, the di-octyl pthalate (DOP) smoke test, and particle analysis with the ROYCO counter. These tests can be done on a contract basis, but an aerosol of bacterial spores provides a simple alternative, which is directly relevant to the function of a biological safety cabinet (Darlow, 1969). Particles in a monodispersed aerosol are 1-3 $\mu$ diameter or less and present the best challenge to a HEPA filter. Smaller particles are trapped more readily because of Brownian movement. This paper describes the methods which were developed for a survey of safety cabinets and some of the results.

\section{Methods}

\section{MICROBIOLOGY}

Bacillus subtilis var globigii (NCTC no. 10073) was used as the indicator organism. Spores were obtained and stored in methanol (Beeby and Whitehouse, 1965); the suspension was diluted with distilled water before use. A strain of Escherichia coli was obtained from routine hospital cultures and used to make a suspension in distilled water. Lemco peptone agar was used as a culture medium and plates were incubated at $37^{\circ} \mathrm{C}$ for 18 hours and then left at room temperature for 24 hours before reading. The aerosols were generated in a Bird (R) micronebulizer (fig 1), obtained from the British Oxygen Company, Pinnacles, Elizabeth Way, Harlow, and operated by compressed air or oxygen. The micronebulizer was calibrated as follows:

The volume of fluid in the aerosol was deduced from the change in weight of the micronebulizer 


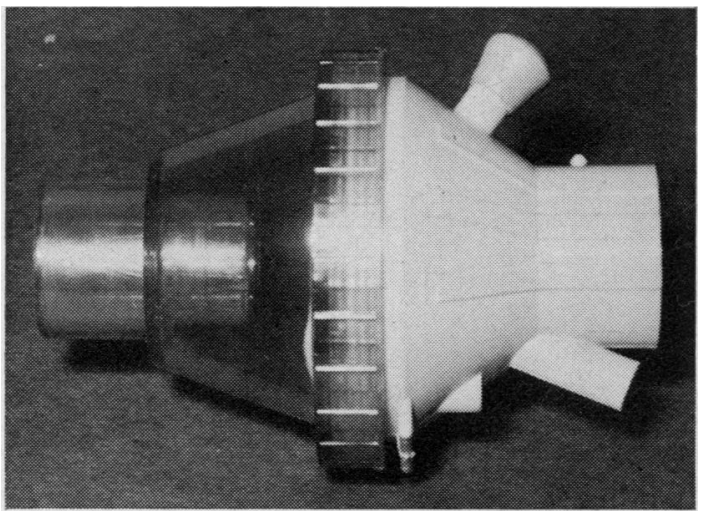

Fig 1 The BIRD micronebulizer (half actual size).

after use; an aerosol was liberated in a 363-1 closed chamber and sampled with a Porton raised capillary impinger (May and Harper, 1957) (from A. W. Dixon and Company, 30 Annerley Station Road, London SE20). The impinger contained $30 \mathrm{ml}$ of impingement fluid (Millipore Technical Service, 1965) $2 \mathrm{~g}$ Bacto gelatin, $4 \mathrm{~g}$ disodium phosphate (anhyd), $37 \mathrm{~g}$ brain-heart infusion, and $0.1 \mathrm{ml}$ antifoam dissolved in 11 water and autoclaved at $15 \mathrm{psi}$ for 15 minutes. The spores were counted by the surface-plate dropping method. The size distribution of spore-containing particles was measured with an Andersen stacked-sieve sampler.

The aerosols used in cabinet tests were investigated with a Casella slit sampler. The volumes of air passing through the impingers and slit sampler were measured with a Rotameter; the impinger operated at 151 per minute and the slit sampler at 281 per minute. The standard test aerosol was generated from $10^{6}$ viable spores per $\mathrm{ml}$ with $10 \mathrm{psi}$ pressure for 10 seconds; the sampling continued for two minutes. Ten tests were run consecutively on each occasion. Extra sets of tests included the use of $10^{8}$ spores per $\mathrm{ml}, 60 \mathrm{psi}$ pressure, and an operator working at the cabinet during the test. Control counts of room air before spraying were included, together with counts performed after release of an aerosol with the cabinet switched off.

The following items were assessed for each cabinet. (1) Escape of bacteria into the room air; the slit sampler was placed in front of the hand holes. (2) Filter integrity; the slit sampler (or an impinger) was connected to the ducting beyond the filter. (3) Deposition of spores on the cabinet floor; two 10 in. square dishes of nutrient agar were exposed on the floor for two minutes after the spray. (4) Incineration units (where supplied) were also challenged with a spray from $10^{6}$ cells per $\mathrm{ml}$ of Escherichia coli to provide a heat-sensitive test organism.
AIRFLOWS

Patterns of flow were visualized with smoke from a
swab dipped in titanium tetrachloride. Air velocity was measured either by a Vane anemometer (Negretti $\stackrel{\rho}{?}$ and Zambra), an electronic anemometer (Airflow Developments, High Wycombe) or a thermistor $\frac{\bar{\sigma}}{\bar{c}}$ anemometer (Prosser Scientific Instruments Limited, $\frac{\hat{\Phi}}{\vec{\sigma}}$ Hadleigh, Suffolk). The output of the two latter $\cong$ machines was fed to a Servoscribe 1s recorder to \% provide permanent records.

\section{CABINETS TESTED}

Twenty-five units from 14 different models were $\frac{\widehat{C}}{3}$ tested. Fourteen were new units, kindly loaned by the manufacturers. Three models exhausted filtered $N$ air to atmosphere by a fan on the window or wall; iv three were laminar flow systems; and the rest re- o turned the treated air (heat or filter) into the room. o Most of the latter models could be connected to exhaust ducts, but an extra fan was sometimes $\vec{c}$ needed to maintain an adequate air flow. The fans ranged from a gramophone motor capable of moving $8 \mathrm{cfm}$ of air to a fan moving $600 \mathrm{cfm}$. The two

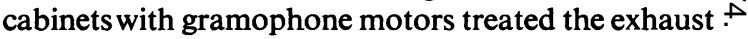
air with a 500-watt heater and returned it to the room. The remainder were fitted with HEPA filters. Fifteen cabinets were given a full test in my laboratory; the remainder were tested on location; some of the latter were fully tested, others merely had $\stackrel{\varnothing}{\mathscr{Q}}$ air flow measurements recorded.

\section{Results}

MICROBIOLOGY

\section{Calibration of micronebulizer}

A fine aerosol was produced at 10 psi which used $\delta$ $0.5 \mathrm{ml}$ per minute while at $60 \mathrm{psi}$ the spray contained many large drops and used $2.2 \mathrm{ml}$ per minute. Many $ᄋ$ particles from both sprays reached the bottom of the sieve sampler and so were 1-2 $\mu$ diameter (fig 2). A 10-second aerosol at 10 psi from $10^{6}$ per ml spores theoretically should have produced 229 per $ᄋ$ litre of air. The average count observed in 14 tests $N$ was 128; thus over half the spores were in the aero- N sol. The release of a similar aerosol inside a cabinet with the ventilation turned off filled the air in front $\underset{c}{\infty}$ of the cabinet with enough spores to produce confluent growth on the slit-sampler plate.

\section{CABINET FUNCTION}

\section{Room air}

Counts up to 5 particles per $2 \mathrm{cu} \mathrm{ft}$ were obtained on $\bar{\sigma}$ occasion with most of the cabinets; similar counts 8 


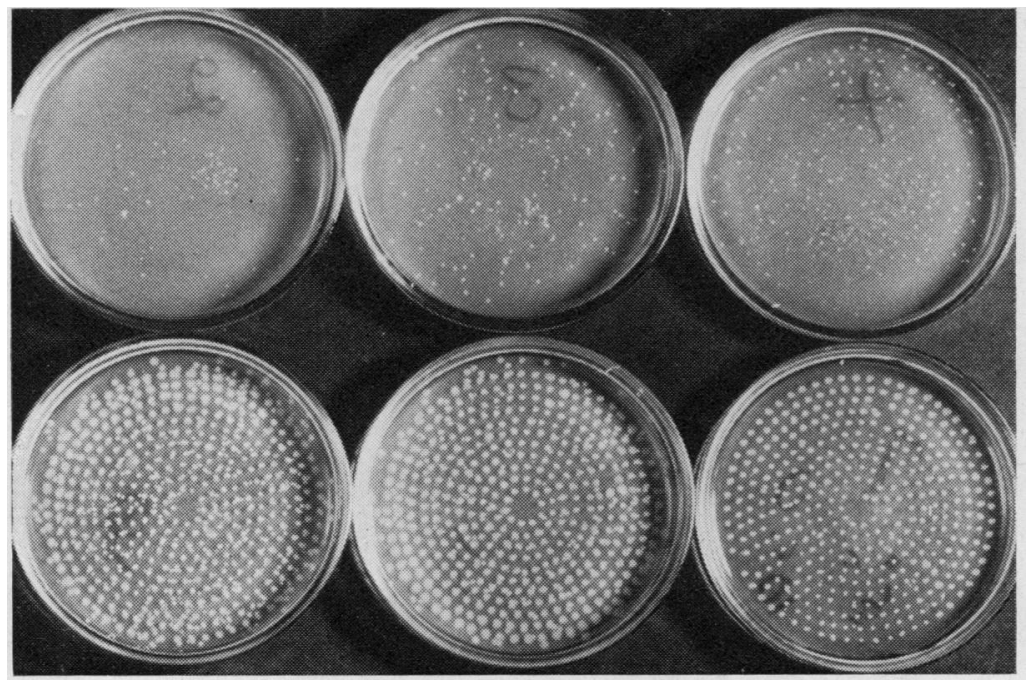

Fig 2 The particle size distribution of an aerosol as measured by the Andersen sampler during stages 2 to 7 (from top left hand corner).

were also found in some of the air controls. Those with an air flow in excess of 0.5 metres per second (100 linear feet per minute) all worked satisfactorily unless there was violent movement near by. Two cabinets with air flows of 0.05 to 0.1 metre per second and two with unrecordable air flows because of blocked filters all released uncountable numbers of spores into the room. A recirculating laminarflow model worked satisfactorily except when the micronebulizer was near the front.

\section{Filter integrity}

No bacteria were detected beyond the filters of five types of new cabinet; average counts of 1.2 particles per $2 \mathrm{cu} \mathrm{ft}$ were found in two samples (one new, one old) of the same model, and in another new cabinet moderate numbers were found to leak around the edge of the filter. By contrast two models which used air incineration liberated large numbers (22-280 per $2 \mathrm{cu} \mathrm{ft}$ ) of spores into the air. These two also liberated similar numbers of $E$. coli.

\section{Deposition of bacteria on cabinet floors}

The number of air changes per minute in the cabinets varied from one to fifty. Very few particles were found on plates when the air changes exceeded nine, but large numbers were found in cabinets with 6.8 , $2 \cdot 1,1 \cdot 2$, and 0.9 changes (see table). The least deposition of all was in the downward laminar flow unit; although the micronebulizer was above the plates and the air flow was towards them, presumably the return of air from the plates acted as a barrier to the spores, and the use of titanium tetrachloride smoke showed an air shadow above the plate.

\begin{tabular}{lcc}
\hline Air Changes per Minute & \multicolumn{2}{c}{$\begin{array}{l}\text { No. of Bacterial Particles Deposited on } \\
\text { 10 in. Square Assay Dish }\end{array}$} \\
\cline { 2 - 3 } & Left Side & Right Side \\
\hline $49 \cdot 75$ & 9 & 2.6 \\
0.89 & 120 & 237 \\
$15 \cdot 7$ & 12 & 11 \\
$1 \cdot 2$ & 123 & Uncountable \\
20 & 2 & 1.6 \\
24 & 16 & 1.6 \\
21 & 120 & 23 \\
6.8 & 359 & 192 \\
32 & 2.3 & 3.3 \\
\hline
\end{tabular}

Table Relationship of cabinet air changes to numbers of bacterial particles deposited on the floor following a standard aerosol spray from the left hand side

\section{Air flows}

The titanium tetrachloride smoke was very useful for the detection of leaks in ducting and could be used to look for turbulence in the air streams. The three anemometers gave similar overall results, but the vane type produced a cumulative reading that had to be divided by the elapsed time and gave no indication of variations in velocity. The electronic type with a direct readout enabled these variations to be seen and recorded. The vanes had an initial inertia and would not move under 0.2 metres per second. The thermistor anemometer had a quick reaction time and measured a smaller cross section, but the accuracy was affected by the probe shield below 0.5 metres per second. The electronic type was more robust and had rechargeable batteries. The face velocity of the air in the different cabinets varied from unrecordable to 1.5 metres per second 
(300 linear feet per minute). The variations in velocity of any cabinet averaged $\pm 20 \%$, but could be higher when someone was working at the cabinet (fig 3) or walking past it.

\section{Discussion}

The BIRD micronebulizer is a simple reflux blast nebulizer and depends on the Bernouilli effect, modified by an anvil (Hayes and Robinson, 1970); it is part of the BIRD ventilator, which is operated at $60 \mathrm{psi}$. However, the aerosol produced by $10 \mathrm{psi}$ is preferable for cabinet tests. The difference between the number of spores in the aerosol and the expected number calculated by weighing the nebulizer could be due to evaporation of up to $50 \%$ of the suspending fluid rather than aerosolization, with consequent concentrations of spores in the remainder (Darlow, personal communication). The number of spores $\left(2.5 \times 10^{4}\right)$ in the standard test, which had been chosen in order to produce confluent growth on the slit sampler plate when a cabinet was switched off, is well above that released in most laboratory manipulations (Reitman and Wedum, 1956; Kenny and Sabel, 1968) and is exceeded only by opening the lid of a blender or the use of an ultrasonic celldisruptor. Most of the cabinets dealt equally well with $2.5 \times 10^{6}$ spores $\left(10^{8}\right.$ per $\left.\mathrm{ml}\right)$, a concentration similar to that used by Barbeito and Taylor (1968).

The micronebulizer was assembled and filled inside a working cabinet to avoid contamination by the room air, and air samples were taken before the liberation of an aerosol. Even so control plates occasionally revealed up to 5 particles per $2 \mathrm{cu} f \mathrm{ft}$ of room air presumably from the operator's hands or clothes or from dust in the rooms, which were not air conditioned. An air scrubber failed to eliminate this undesirable background, although it was effective in reducing the total bacterial count in room air.
The performance of tests in sets of 10 pro- $v$

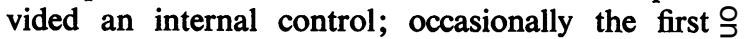
count would be high and subsequent ones would tail off, indicating a technical hitch. Wedum (1964) assumed that the inhalation of 10 particles in five minutes, ie, $2 \mathrm{cu} f t$ of air, constituted a human infec- $\vec{\theta}$

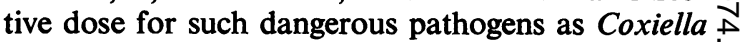
burneti and Franciscella tularensis. Our equivocal counts were below this; on the other hand there was little doubt about the results from an inadequate cabinet because the slit sampler plate exposed outside it usually displayed heavy or confluent growth. The two new units which liberated large numbers of spores into the room and had a low air flow were those that worked on air incineration and have since been withdrawn from sale.

The results of the tests on the filtered air were excellent. The $99.997 \%$ efficiency implies that 3 용 particles per 100000 might pass through; in practice most of the filters were more efficient. However, the standard burst of spores appears in retrospect to 8 have been inadequate; later tests used $10^{5}$ spores but a two-minute spray from $10^{8}$ per $\mathrm{ml}$ would be a 응 better challenge. The fact that a filter might not be a $>$ total barrier to a very heavy concentration of bac- 을. teria could be important; in this case it would be essential to duct the effluent out of the laboratory or $\sigma$ to use two filters in series. The infected exhaust from $N$ the two cabinets which worked on air incineration $N$ was recycled into the room and so made these $\sigma$ cabinets doubly hazardous. Line (1972) obtained similar results on one of these models.

Although the initial work was aimed at tests on new machines, those on other installations were very 0 revealing. New equipment rarely worked as well as $\overrightarrow{0}$ in the test laboratory. The length, type, and geometry $\mathbb{\AA}$ of connexion ducts were important; the drain pipe $\mathbb{\mathbb { D }}$ type has much better air flow characteristics than the ribbed variety. The use of 10 extra feet of the latter 
reduced the air flow from 0.7 to 0.15 metres per second in one installation, and in several others higher duty fans were required to overcome duct resistence. Two installations failed because of holes between the fan and filter, one contained a faulty junction, and the other was due to the use of the same fan and ducting for a fume cupboard in an adjoining biochemistry department (unbeknown to the microbiologist). Faulty maintenance was also evident: several of the cabinets tested in situ had blocked filters, and two instances have come to light in which replacement filters were incorrectly bedded down in laminar-flow units.

Thus there are many pitfalls in the selection, installation, and use of biological safety cabinets and operators should be able to test them. The micronebulizer worked well, cost $£ 6 \cdot 50$, and was readily available. The Wright's nebulizer is another simple and cheap unit, often used in the physiotherapy department for aerosol inhalations. An impinger cost about $£ 2.00$ and gas cylinders and pumps are usually to hand in the laboratory. The electronic anemometer was robust and foolproof, it cost around $£ 100 \cdot 00$, while the thermistor type was $£ 52.00$. Cost, therefore, is not a deterrent. The cabinets should be tested with spore tests and the anemometer at monthly intervals; more complex tests such as the use of DOP could be done on a contract basis; to test a new installation, after changing filters (particularly on laminar flow models) and possibly at yearly intervals.
This work is part of a study carried out for the Department of Health and Social Security through study group number 9 of its Engineering Division, to which I am very grateful for financial support.

I am most grateful to Surgeon Commander H. M. Darlow for his advice and encouragement.

\section{References}

Barbeito, M., and Taylor, L. A. (1968). Containment of microbial aerosols in a microbiological safety cabinet. Appl. Microbiol., $16,1225-1229$.

Beeby, M. M., and Whitehouse, C. E. (1965). A bacterial spore test piece for the control of ethylene oxide sterilization. J. appl. Bact., 28, 349-353.

Darlow, H. M. (1969). Safety in the microbiological laboratory. Meth. Microbiol., I, p. 191.

Darlow, H. M. (1974). Personal communication.

Dyment, J. (1974). Personal communication.

Hayes, B., and Robinson, J. S. (1970). An assessment of methods of humidification of inspired gas. Brit. J. Anaesth., 42, 94-104.

Kenny, M. T., and Sabel, F. L. (1968). Particle size distribution of Serratia marcescens aerosols created during common laboratory procedures and simulated laboratory accidents. Appl. Microbiol., 16, 1146-1150.

Line, S. J. (1972). Safety of portable inoculation cabinets. J. clin. Path., 25, 93-94.

May, K. R., and Harper, G. J. (1957). The efficiency of various liquid impinger samplers in bacterial aerosols. Brit. J. ind. Med., 14, 287-297.

Millipore Corporation (1965). Techniques for Microbiological Analysis, p. 12. Millipore Technical Service, Bedford, Mass.

Reitman, M., and Wedum, A. G. (1956). Microbiological Safety. Publ. Hlth Rep. (Wash.), 71, 659-665.

Wedum, A. G. (1964). Laboratory safety in research with infectious aerosols. Publ. Hlth Rep. (Wash.), 79, 619-633.

Williams, R. E. O., and Lidwell, O. M. (1957). A protective cabinet for handling infective material in the laboratory. J. clin. Path. 10, 400-402. 